\title{
Effects and interaction of different interior material treatment and personal preference on psychological and physiological responses in living environment
}

Minkai Sun ${ }^{1,2}$, Taisuke Nakashima ${ }^{1}$, Yuri Yoshimura ${ }^{1}$, Akiyoshi Honden ${ }^{1}$, Toshinori Nakagawa ${ }^{1,3}$, Hiromi Saijo ${ }^{1}$, Yuichiro Watanabe ${ }^{4}$, Tsuyoshi Ajimi ${ }^{4}$, Shinji Yasunari ${ }^{5}$, Yuki Yamada 6 , Jun Nagano ${ }^{7}$, Tsuyoshi Okamoto ${ }^{6}$, Hiroya Ishikawa ${ }^{8}$, Koichiro Ohnuki $^{9}$, Noboru Fujimoto $^{1}$ and Kuniyoshi Shimizu ${ }^{1 *}$ (i)

\begin{abstract}
Japanese cedar (Cryptomeria japonica) wood is widely used as a traditional construction material in Japan. The relationship between an individual's perceived comfort level and a preference for Japanese cedar wood interiors is of interest. We compared volunteers' physiological responses and subjective evaluations of wooden dwelling spaces with different wood materials: planed Japanese cedar lumber, or printed grain resin sheet overlay boards. Eightythree subjects were asked to stay in each room for $30 \mathrm{~min}$. We evaluated salivary stress markers, blood pressure, the profile of mood states-brief form (POMS), and a questionnaire that used the semantic differential method to evaluate the subjects'feeling state for both rooms. The concentrations of the volatile organic compounds in both rooms were also quantified after the experiment. The results demonstrated that the subjects' evaluation of each room was highly dependent on their preference; each room was evaluated more positively by subjects who preferred it. Although the subjects' feelings were also influenced by their preference, the room with Japanese cedar did not elicit negative feelings, even from the subjects who disliked it. The subjects' physiological responses were totally independent of their preferences. Their blood pressure decreased in the Japanese cedar room, and their salivary alpha-amylase activity was repressed in both rooms. These results indicated that the subjective evaluations were influenced in part by the subjects' preferences, while their physiological responses were not affected. Regardless of which room the subjects preferred, the Japanese cedar room reduced the subjects' blood pressure compared to the room with artificial materials.
\end{abstract}

Keywords: Japanese cedar, Cryptomeria japonica, Preference, Physiological response, Psychological response

\section{Introduction}

Wood has been used as a material in construction and interior decoration in Japan since ancient times. The smell and appearance of wood materials were recently reported to affect humans' physiological and psychological responses [1-7]. The smell of wood materials is

\footnotetext{
${ }^{*}$ Correspondence: shimizu@agr.kyushu-u.ac.jp

${ }^{1}$ Faculty of Agriculture, Kyushu University, 744 Motooka, Nishi-ku,

Fukuoka 819-0395, Japan

Full list of author information is available at the end of the article
}

thought to contribute to a room's perceived comfort level. Subjects who inhaled the smell of Japanese cedar (Cryptomeria japonica) described a 'natural' and 'peaceful' feeling; their pulse rates also decreased slightly. That study's authors concluded that the Japanese cedar smell has a relaxant effect on humans [5]. It has also been shown that inhaling Japanese cypress wood oil can reduce the oxy$\mathrm{Hb}$ concentration in the right prefrontal cortex of human subjects while enhancing parasympathetic nervous activity [8]. 
Other researchers asked subjects to do arithmetic in rooms with and without the smell of Japanese cedar, and they observed that during and after the completion of the arithmetic only in the room without the Japanese cedar smell, the ratio of the low-frequency (LF) component to the high-frequency (HF) component (LF/HF) of the subjects' heart rate variability (HRV) was increased, and their salivary alpha-amylase (SAA) levels were increased [6]. When people were exposed to Japanese cedar chips, their frontal activity was reduced and their blood pressure declined [9]. A later study described how the smell of wood suppressed the activities of the sympathetic nervous system and promoted the feeling of a 'natural' environment [10]. Many studies, including those mentioned above, indicated that the effects of wood-derived stimulation can provide multiple physiological and psychological benefits such as stress reduction, task performance improvement, blood pressure reduction, and more. However, different types and concentrations of a woody smell can influence the level of subjective comfort. Several research groups have reported that the relationships between the concentration of smells and various emotions are complex; for example, some researchers found that inhaling a high concentration of $\alpha$-pinene triggers a feeling of discomfort $[10,11]$.

In addition, the effects of the smell of wood on physiological responses do not necessarily correspond to individual preferences. Subjects' SAA activity and blood pressure were lower in a room with limited wood material compared to one with more wood, and these values did not correspond to the results from the subjects' evaluations, which indicated that they preferred rooms with more wood [2]. The effect of a woody smell on people's physiological and psychological responses depended on the smell's concentration [10]. However, even subjects who reported disliking the smell of Japanese cedar showed no increase in blood pressure with exposure to the smell [3].

As one of the varieties of construction materials, printed grain resin sheet overlay boards have been widely used as imitation woo. The appearance of the room using these boards as the interior material is almost the same as that of the room using the real wood. However, the composition of printed grain resin sheets is quite different from real wood. The volatile organic compounds (VOCs) in the room with the imitation-wood grain vinyl covering as an interior material were, thus, suspected to be different from the VOCs in the room with real wood, and they may elicit different physiological and psychological responses.

We, therefore, performed a quantitative analysis of VOCs in the rooms, and we compared the psychological and physiological human responses between the rooms with two different types of wood interior coverings: planed Japanese cedar lumber and printed grain resin sheet overlay boards.

\section{Materials and methods \\ Experimental rooms}

Two interiors were constructed at Kyushu University in October 2012 (Fig. 1). The rooms were the same size and had almost the same lighting conditions (floor space, $10 \mathrm{~m}^{2}$; ceiling height, $2.4 \mathrm{~m}$; room interior volume, $24 \mathrm{~m}^{3}$ ). Room A had planned Japanese cedar lumber as the interior material; this lumber, dried at $50-60{ }^{\circ} \mathrm{C}$, was used for the floor (thickness $15 \mathrm{~mm}$ ), the four walls, and the ceiling (thickness $12 \mathrm{~mm}$ ). The room's foundation, pillars, crossbeams, and beams were composed of planed Japanese cedar lumber dried in a drying set at $120^{\circ} \mathrm{C}$ and then under reduced pressure at $50-60{ }^{\circ} \mathrm{C}$. The inside and outside surfaces of the door of Room A were covered by wood grain sheets.

As interior materials, Room B had wood-based materials covered with an imitation-wood vinyl covering and painted interior sections. Medium density fiberboard (MDF) (thickness $6 \mathrm{~mm}$ ) with a UV coating was used for the floor $\left(7.3 \mathrm{~m}^{2}\right)$. Particleboard was used as the substrate material for the walls (thickness $12.5 \mathrm{~mm}$ ) and the ceiling $(9.5 \mathrm{~mm})$, and the surfaces were covered with an imitation-wood vinyl covering. The material of the foundation, pillars, crossbeams, and beams was Japanese cedar lumber dried at high temperature $\left(90-120{ }^{\circ} \mathrm{C}\right.$ for 6 days). The inside of the door of Room B was covered by the same wood grain sheets as used for the door of Room A, and its outside surface was covered by wood grain sheets.

All of the materials used in both rooms emitted an amount of formaldehyde conforming to Fis nese Industrial Standard, formaldehyde emission limit: $0.5 \mathrm{mg} / \mathrm{L}$ ) [12]. It has been demonstrated that the main atmospheric VOCs of the two rooms were essentially the same [13]. Room A had a higher level of VOCs (mainly terpenes) compared to Room B.

The door of Room A had a wood grain sheet on both sides, and the door of Room B had the same wood grain sheet as that used for the Room A door on its inside surface but a plain sheet on the outside.

\section{The subjects}

The human research protocols for the study were approved by the Ethics Committee of the College of Agriculture at Kyushu University (No. 21). Eightythree healthy adults (mean age \pm standard deviation: $37.1 \pm 14.7$ years) were recruited for the study: 32 males $(38.9 \pm 16.4$ years) and 51 females (36.0 \pm 13.5 years). None of the subjects reported having any abnormal physical or mental health conditions. All subjects were 


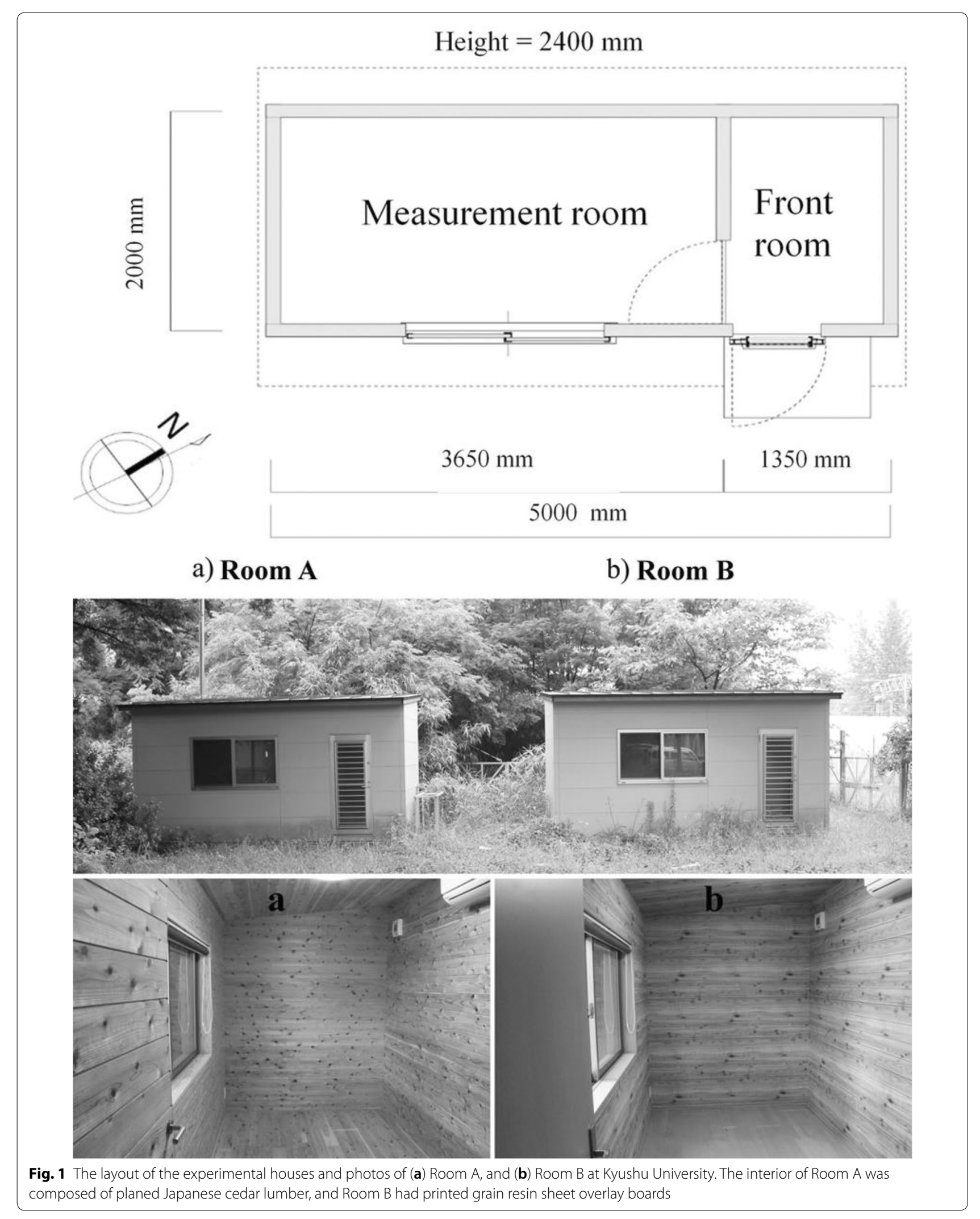


informed about the study's purpose (i.e., to investigate the effects of the smell of wood) so that the subjects were expected to pay more attention to the smell of the room's atmosphere rather than its visual features; the researchers did not mention the differences in interior materials used in the two rooms. Written informed consent was obtained from all subjects. The subjects were asked to refrain from taking medications or supplements, consuming foods or beverages containing alcohol or caffeine, or participating in vigorous sports 1 day before and on the day of the experiment. The subjects received compensation after completing the experiment. All of the subjects select their responses themselves. All of the experiments were performed in January or February of 2014.

\section{Measurements \\ Temperature, humidity, and volatile organic compounds (VOCs)}

The temperature and humidity in each room were recorded by a hygrothermograph (Data Logger TR72Ui: T\&D Corp., Matsumoto, Japan) after each subject's entrance and before his or her exit from the room. After all of the experiments were finished in March 2014, three pumps attached to sorbent tubes (Tenax TA; Gerstel, Linthicum, MD) were set in the two rooms and started simultaneously to collect VOCs (flow rate: 0.15 L/min, amount: $9 \mathrm{~L}$, duration: $60 \mathrm{~min}$ ). Sorbent tubes were thermally desorbed to a gas chromatography-mass spectrometry system (GC/MS; 7890A/5975C, Agilent Technologies, Santa Clara, CA) with a thermal desorption unit (TDU) (Gerstel). Samples were injected in the splitless mode. The GC/MS was equipped with a DB$5 \mathrm{MS}$ column $(30 \mathrm{~m} \times 0.25 \mathrm{~mm}$; $0.25-\mu \mathrm{m}$ film thickness; Agilent Technologies). Cryo-injection (from - 100 to $40{ }^{\circ} \mathrm{C}$ in $15 \mathrm{~min}$ ) allowed VOCs to enter the injection port of the GC/MS system. The oven temperature program was $60{ }^{\circ} \mathrm{C}$ for $5 \mathrm{~min}$ and was increased to $230^{\circ} \mathrm{C}$ at $3{ }^{\circ} \mathrm{C} /$ $\mathrm{min}$, then held at this temperature for $30 \mathrm{~min}$. Helium was used as the carrier gas at a flow rate of $1 \mathrm{ml} / \mathrm{min}$.

For the quantitative analysis, $1 \mu \mathrm{L}$ of benzaldehyde solution $(200 \mu \mathrm{L} / \mathrm{L}$, acetone $)$ was added as the internal standard. A calibration curve was prepared using $\beta$-caryophyllene (one of the sesquiterpenes) to determine the concentration of each volatile component as the $\beta$-caryophyllene equivalent. The limit of quantification (LOQ) was determined as the concentration with a signal-to-noise ratio $(\mathrm{S} / \mathrm{N})$ of 10 . We focused on sesquiterpenes, which are the main VOCs of Japanese cedar wood. We identified the sesquiterpenes contained in the VOCs by comparing the mass spectrum with the National Institute of Standards and Technology mass spectral library (NIST 11.0). We determined the Kovats retention index
(RI) using Aroma Office software ver. 7.0 (Nishikawa Keisoku, Tokyo).

\section{Physiological responses}

The subjects' salivary alpha-amylase activities were measured as a stress marker after they entered and before they exited each room (Salivary amylase monitor CM-2.1; Nipro Corp., Osaka, Japan). To determine whether the changing ratio of SAA differed between the two rooms, we calculated the changing ratio of SAA using the following formula:

$$
\begin{aligned}
& \text { Changing ratio }=\text { (score before exit } \\
& - \text { score after entrance) } / \text { score after entrance. }
\end{aligned}
$$

Blood pressure and pulse rate were also measured twice after the subjects entered the rooms and twice before exiting (Terumo Electronic Sphygmomanometer P2000; Terumo Corp., Kakamigahara, Japan) to reduce the measurement error by averaging.

\section{Subjective evaluations}

For the assessment of their overall subjective feelings associated with the rooms (including aroma and interior design), the subjects were asked to fill out a questionnaire using a semantic differential (SD) method [14]. Based on the previous studies $[10,15]$, the following 17 pairs of adjectives were used in this study: comfortable-uncomfortable, bright-dark, natural-artificial, warm-cold, bright-dark, soft-hard, calm-tense; (visual) light-heavy, (visual) natural-artificial, (visual) refreshed-unrefreshed, (smell) light-strong, (smell) refreshed-unrefreshed, (smell) light-heavy, (smell) natural-artificial; accessibleinaccessible, cold-warm, simple-intricate, not tiredtired, secure-insecure, (feel can do work) well-not well. A visual analog scale (VAS) was used to identify the position of each word along a continuous line $(0-100 \mathrm{~mm})$ between the two end-points. The subjects were asked to make a mark on the line that fit their intuitive feeling in response to the room.

To investigate the distinct perceptions of the smell in the room, we administered a questionnaire containing the following nine words, each on a visual scale of 0-100 mm: sweet, sour, perfumed, soft, spicy, bitter, fresh, refreshing, and calm. For the evaluation of the emotional feeling regarding each room's odor, we administered a questionnaire containing seven pairs of words: like (0)-dislike (100), cozy (0)-not cozy (100), not tired (0)-tired (100), balmy (0)-violent (100), calm (0)-rough (100), unrefreshing (0)-refreshing (100), and light (0)strong (100) in the VAS format. The VAS scores were measured using a ruler.

To assess the subjects' mood states, we used the short form of the Profile of Mood States (POMS-SF) [16]. The 
subjects were asked to check a five-point scale ranging from 'not at all' to 'extremely' for all 30 questions on the POMS-SF before leaving either room. The POMSSF questions were assigned to six different subscales of mood: Tension-Anxiety (T-A), Anger-Hostility (A-H), Vigor (V), Fatigue (F), Depression (D), and Confusion (C). T-scores were calculated according to the POMS manual, and mood states were assessed quantitatively [16]. For the identification of each subject's preferences, each was asked to disclose their preferred room and to state the reason(s) why they preferred the room after they had finished their stays in both rooms.

\section{Experimental procedure}

For each room, an air conditioner and humidifier were used to set the temperature in the range of $16-18{ }^{\circ} \mathrm{C}$ and humidity in the range of $40-50 \%$. The air conditioner, humidifier, and ventilating fan were turned off during the experimental period. A passive ventilation system was adapted via a $15-\mathrm{cm}$-diameter hole in one wall. After the subject arrived at the test site, he or she was asked if their physical condition was good. The subject was also asked to use the restroom before entering a room, to avoid the need to leave the room during the experiment. Although the inside surfaces of the doors of both rooms were covered by the same type of wood grain sheet, the door of Room B had a subtly different surface compared to Room $\mathrm{A}$, and the subjects were asked to evaluate the interior smell of each room before entering the room. Once in the room, the single subject was asked to sit on a chair for $10 \mathrm{~min}$ to rest and evaluate the room. After the evaluation, the subject's blood pressure and pulse rate were measured twice.

The SAA activity was measured after the blood pressure was measured the second time. The tip of the salivary meter was put under the subject's tongue to immerse it in saliva for $30 \mathrm{~s}$, and SAA activity was measured by salivary amylase monitor. The subject was then instructed to fill out a POMS-SF form and the three questionnaires. After these were finished, the subject's salivary alpha-amylase activity, blood pressure, and pulse rate were measured again. Each subject stayed in each room for approx. $30 \mathrm{~min}$. To avoid sequential effects, the order of the room exposure was randomly determined. Each subject went from the 'first' room to the 'second room' after a 1-week interval. Finally, the subject was asked to choose his or her preferred room (Table 1).

\section{Statistical analyses}

We used paired $t$-tests to compare the rooms' VOC concentration, temperature, and humidity. Data from the three questionnaires regarding the subjects' feeling about the rooms, the rooms' distinct perceptual characteristics, and the rooms' smells were subjected to a factor analysis to extract factors (maximum-likelihood method, promax rotation, eigenvalues $>1$ ). Logarithmic transformation was performed for the salivary alpha-amylase activity to approximate a normal distribution. All subjects were assigned to one of the two groups, depending on their room preference: The W group (wood was preferred) liked room A $(n=49)$, and the $\mathrm{L}$ group (laminate preferred) liked room B $(n=34)$. A multivariate repeatedmeasures analysis of variance (MANOVA) followed by Bonferroni post hoc tests were conducted using the mean blood pressure, mean pulse rate, and salivary alpha-amylase activity, using all of the subjects' data. The betweensubjects factor was groups (W group vs. L group), and the within-subjects' factors were timing (after entrance, before exit) and room (room A, room B).

A two-way repeated-measures ANOVA followed by Bonferroni post hoc tests was conducted on the T-score of the POMS-SF and the factor scores of all questionnaires. The between-subjects factor was group (W vs. L), and the within-subjects factor was room (A vs. B). In all cases, the significance level was set at $p<0.05$. The effect size is shown by partial eta-squared $\left(\eta p^{2}\right)$ defined by the following formula.

$$
\eta p^{2}=\mathrm{SS}_{\text {effect }} /\left(\mathrm{SS}_{\text {effect }}+\mathrm{SS}_{\text {error }}\right)
$$

where SS represents the sum of squares of analysis of variance. We used the values of $0.01,0.06$, and 0.14 to indicate small, medium, and large associations between the variables, respectively $[17,18]$. All statistical analyses were performed with SPSS ver. 19.0 (IBM, Armonk, NY). The statistical powers for each post hoc analysis were calculated using R ver. 3.5.1. All of the data are shown as the mean $\pm 95 \%$ confidence interval $(\mathrm{CI})$.

Table 1 Time schedule of experimental procedure

\begin{tabular}{c|c|c|c|c|c|c|c}
1 & 2 & 3 & 4 & 6 & 7 \\
$\begin{array}{l}\text { Sit and } \\
\text { calm } \\
\text { down }\end{array}$ & $\begin{array}{l}\text { Blood } \\
\text { pressure } \\
\text { pulse rate }\end{array}$ & $\begin{array}{l}\text { Salivary } \\
\text { amylase } \\
\text { activity }\end{array}$ & POMS & $\begin{array}{c}\text { Impression } \\
\text { evaluation }\end{array}$ & $\begin{array}{l}\text { Salivary } \\
\text { amylase } \\
\text { activity }\end{array}$ & $\begin{array}{l}\text { Blood } \\
\text { pressure } \\
\text { pulse rate }\end{array}$ & \\
\hline $10 \mathrm{~min}$ & $2 \mathrm{~min}$ & $2 \mathrm{~min}$ & $5 \mathrm{~min}$ & $7 \mathrm{~min}$ & $2 \mathrm{~min}$ & $2 \mathrm{~min}$ &
\end{tabular}




\section{Results}

\section{Physiological responses}

The analysis of the subjects' systolic blood pressure (SBP) revealed that regardless of the subjects' preference, the SBP of $76.0 \%(n=63)$ of the 83 subjects (W group, $n=37$; L group, $n=26$ ) decreased by an average of $7 \mathrm{mmHg}$ after they stayed in room A. The SBP of $22.9 \%(n=19)$ of the 83 subjects (W group, $n=12$; L group, $n=7$ ) increased by an average of $4 \mathrm{mmHg}$ after they stayed in Room $\mathrm{A}$. One subject's SBP did not change (in either room).

In the case of Room B, a decrease in SBP by an average of $7 \mathrm{mmHg}$ occurred in $69.0 \%(n=57)$ of the 83 subjects (W group, $n=36$; L group, $n=21$ ); whereas, an increase in the SBP by an average of approx. $8 \mathrm{mmHg}$ was observed in $30.1 \%(n=25)$ of the subjects (W group, $n=12$; L group, $n=13$ ).

The results of statistical analysis revealed a significant main effect of timing in the case of Room A $(F$ $\left.(1,81)=7.568, \quad p=0.007, \eta p^{2}=0.085,1-\beta=0.776\right)$. The pairwise comparisons for the main effect showed lower SBP in all of the subjects who stayed in Room A before exiting compared to the SBP after their entrance (before exiting: $111 \pm 12 \mathrm{mmHg}$ vs. after entrance: $\left.114 \pm 13 \mathrm{mmHg}, p=0.007, \eta p^{2}=0.085,1-\beta=0.776\right)$. The SBP was decreased in both the W group (before exiting: $108 \pm 15 \mathrm{mmHg}$ vs. after entering: $112 \pm 16 \mathrm{mmHg}$, $\left.p=0.009, \eta p^{2}=0.081,1-\beta=0.754\right)$ and the $\mathrm{L}$ group (before exiting: $114 \pm 19 \mathrm{mmHg}$ vs. after entering: $\left.119 \pm 20 \mathrm{mmHg}, p=0.008, \eta p^{2}=0.022,1-\beta=0.265\right)$ after they stayed in Room A; whereas, no significant change in SBP was observed after the subjects stayed in Room B.

Regarding the subjects' pulse rate, regardless of their room preference, the pulse rate of $47.0 \%(n=39)$ of the 83 subjects (W group, $n=26$; L group, $n=13$ ) decreased by an average of $3 \mathrm{bpm}$ after they stayed in Room A; whereas, an approx. 3-bpm increase in the pulse rate was detected in $48.2 \%(n=40)$ subjects (W group, $n=12$; L group, $n=13$ ) after their stay in Room A. The remaining four subjects' pulse rates were not changed by their stay in Room A.

In the case of Room B, the pulse rate of $59.0 \%(n=49)$ of the 83 subjects (W group, $n=28$; L group, $n=21$ ) decreased by an average of $4 \mathrm{bpm}$, and an average 3 -bpm increase in the pulse rate occurred in $39.8 \%(n=33)$ subjects (W group, $n=21$; L group, $n=13$ ). The remaining subject's pulse rate was not changed in Room B.

The results of the statistical analysis revealed a significant main effect of timing in the case of Room B ( $F$ $\left.(1,81)=6.789, p=0.011, \eta p^{2}=0.077,1-\beta=0.731\right)$. The pairwise comparisons of all subjects for the main effect showed a lower pulse rate before exiting the room than after the entrance (before exit: $69 \pm 7$ vs. after entrance: $\left.70 \pm 8, p=0.011, \eta p^{2}=0.077,1-\beta=0.731\right)$. The pulse rate was decreased in both the $\mathrm{W}$ group (before exiting: $68 \pm 10$ bpm vs. after entering: $69 \pm 10 \mathrm{bpm}, p=0.009$, $\eta p^{2}=0.025,1-\beta=0.295$ ) and the L group (before exiting: $69 \pm 12$ bpm vs. after entering: $71 \pm 12 \mathrm{bpm}, p=0.005$, $\eta p^{2}=0.056,1-\beta=0.583$ ) after they stayed in Room B; whereas, no significant change in pulse rate was observed after the subjects stayed in Room A (Fig. 2).

For the SAA, regardless of the subjects' preference, the SAA of $56.6 \%(n=47)$ of the 83 subjects (W group, $n=24$; L group, $n=23$ ) decreased by an average of 0.58 $\mathrm{KU} / \mathrm{L}$ after they stayed in Room A. The SAA of $22.9 \%$ ( $n=36$ ) of the subjects (W group, $n=25$; L group, $n=11$ ) increased by an average of $0.42 \mathrm{KU} / \mathrm{L}$ after their $30 \mathrm{~min}$ in Room A.

In the case of Room B, the SAA of $60.2 \% \quad(n=50)$ of the 83 subjects (W group, $n=32$; L group, $n=18$ ) decreased by an average of $0.63 \mathrm{KU} / \mathrm{L}$; whereas, that of the other 31 subjects (37.3\%) (W group, $n=15$; L group, $n=16)$ increased by approx. $0.49 \mathrm{KU} / \mathrm{L}$. There was a significant main effect of timing in the case of Room A ( $F$ $\left.(1,81)=4.190, p=0.044, \eta p^{2}=0.049,1-\beta=0.525\right)$. The pairwise comparisons for the main effect showed lower SAA in all subjects before the room exit compared to after the entrance (before exiting: $4.27 \pm 0.18$ vs. after entering: $\left.4.43 \pm 0.16 ; p=0.044, \eta p^{2}=0.049,1-\beta=0.525\right)$. The SAA was decreased both in $\mathrm{W}$ group (before exiting: $4.32 \pm 0.22$ vs. after entering: $4.37 \pm 0.21, p=0.016$, $\eta p^{2}=0.03,1-\beta=0.407$ ) and $\mathrm{L}$ group (before exiting: $4.21 \pm 0.30$ vs. after entering: $4.49 \pm 0.22, p=0.002$, $\left.\eta p^{2}=0.060,1-\beta=0.615\right)$. The same was true of Room B $\left(F(1,81)=4.953, p=0.029, \eta p^{2}=0.058,1-\beta=0.595\right)$, in which the pairwise comparisons of all subjects for the main effect showed lower SAA before the room exit than after the entrance to the room (before exiting: $4.15 \pm 0.17$ $\mathrm{KU} / \mathrm{L}$ vs. after entrance: $4.35 \pm 0.17 \mathrm{KU} / \mathrm{L}, p=0.029$, $\left.\eta p^{2}=0.058,1-\beta=0.595\right)$. The SAA was decreased in both the W group (before exiting: $4.21 \pm 0.24 \mathrm{KU} / \mathrm{L}$ vs. after entering: $4.42 \pm 0.21 \mathrm{KU} / \mathrm{L}, p=0.016, \eta p^{2}=0.043$, $1-\beta=0.467$ ) and the $\mathrm{L}$ group (before exiting: $4.09 \pm 0.25$ $\mathrm{KU} / \mathrm{L}$ vs. after entering: $4.27 \pm 0.28 \mathrm{KU} / \mathrm{L}, p=0.009$, $\eta p^{2}=0.021,1-\beta=0.255$ ) (Fig. 3).

\section{Subjective evaluations}

Regarding the T-A sub-scale of the POMS-SF, 26 subjects (W group, $n=11$; L group, $n=15$ ) gave a higher score to Room A than Room B; 35 subjects (W group, $n=25$; L group, $n=10$ ) gave a higher score to Room $\mathrm{B}$, and the remaining 22 subjects gave the same score to both rooms. A significant interaction was found between room and group. The W group's T-score for Room A was lower than that for Room B. For the V sub-scale of the POMS-SF, 40 subjects (W group, $n=31$; L group, $n=9$ ) gave a higher score to Room A than Room B. 31 subjects 


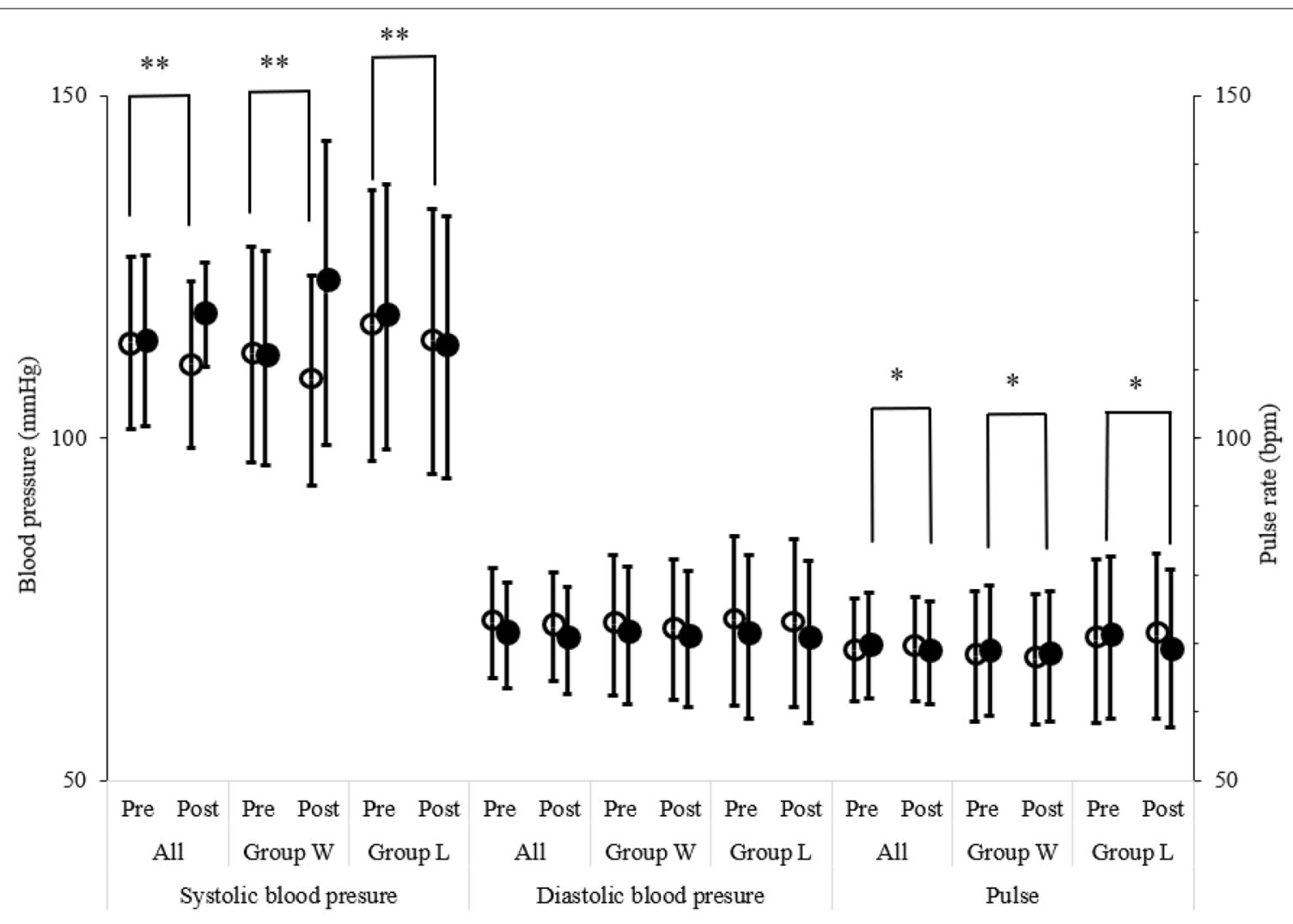

O Room A Room B

Fig. 2 The variation in blood pressure and pulse rate between the rooms A and B at pre-(entering) and post-(exiting) measurements by the $W$ and $\mathrm{L}$ groups. Each point represents the mean value in room A (white) and room B (black). In the case of room A, compared to the pre-condition, the SBP of both the W and $L$ groups at the post-measurement was lower. In the case of room B, compared to the pre-condition, the pulse rate of both the $W$ and $L$ groups at the post-measurement was lower. Data are shown as mean $\pm 95 \% \mathrm{Cl}$. Statistical significance was determined at $p<0.05$ by a MANOVA; ${ }^{* *} p<0.01,{ }^{*} p<0.05$

(W group, $n=11$; L group, $n=20$ ) gave a higher score to Room B, and the remaining 12 subjects gave the same score to both rooms. There was an interaction between room and group, with the $\mathrm{W}$ group having a higher T-score than Room B.

For the F sub-scale of the POMS-SF, 15 subjects (W group, $n=5$; L group, $n=10$ ) gave a higher score to Room A compared to Room B; 23 subjects (W group, $n=19 ; \mathrm{L}$ group, $n=4)$ gave a higher score to Room B. Most of the subjects ( $n=45$ total, W group, $n=25$, L group, $n=20$ ) felt indifferent about the two rooms. The results revealed a significant interaction between room and group. The W group's T-score for Room A was lower than that for Room B. For the C sub-scale of the POMS-SF, 31 subjects gave Room A a higher score (W group, $n=15$; $\mathrm{L}$ group, $n=16$ ); a different 31 subjects gave Room $\mathrm{B}$ a higher score (W group, $n=23$; L group, $n=8$ ), and the remaining 21 subjects gave the two rooms the same score (W group, $n=11$; L group, $n=10$ ). Moreover, on the $\mathrm{D}$ sub-scale of the POMS-SF, 13 subjects (W group, $n=5$;
L group, $n=8$ ) gave a higher score to Room A than Room $\mathrm{B}$, and 27 subjects (W group, $n=18$; L group, $n=9$ ) gave a higher score to Room B. Most of the subjects $(n=43$ total, W group, $n=26$, L group, $n=17$ ) gave the two rooms the same score. The statistical analysis showed a marginally significant interaction between room and group. The W group's T-score for Room A was marginally lower than that for Room B (Table 2).

The SD questionnaire included 17 pairs of adjectives. The eigenvalue was assumed to be $\geq 1$. Seven repetitions resulted in the end of the rotation, and four explicable factors were extracted. Table 3 shows the extracted factors and factor loadings. The initial eigenvalues showed that factor 1 was 7.71 , factor 2 was 1.53 , factor 3 was 1.31 , and factor 4 was 1.02 . The four-factor solution explained $68.06 \%$ of the variance (Table 3). Adjectives comprising factor 1 were related to how comfortable the subjects felt in the room; thus, factor 1 was designated as the level of comfort.' Adjectives comprising factor 2 were related to the subjects' evaluation of the sensory quality; factor 


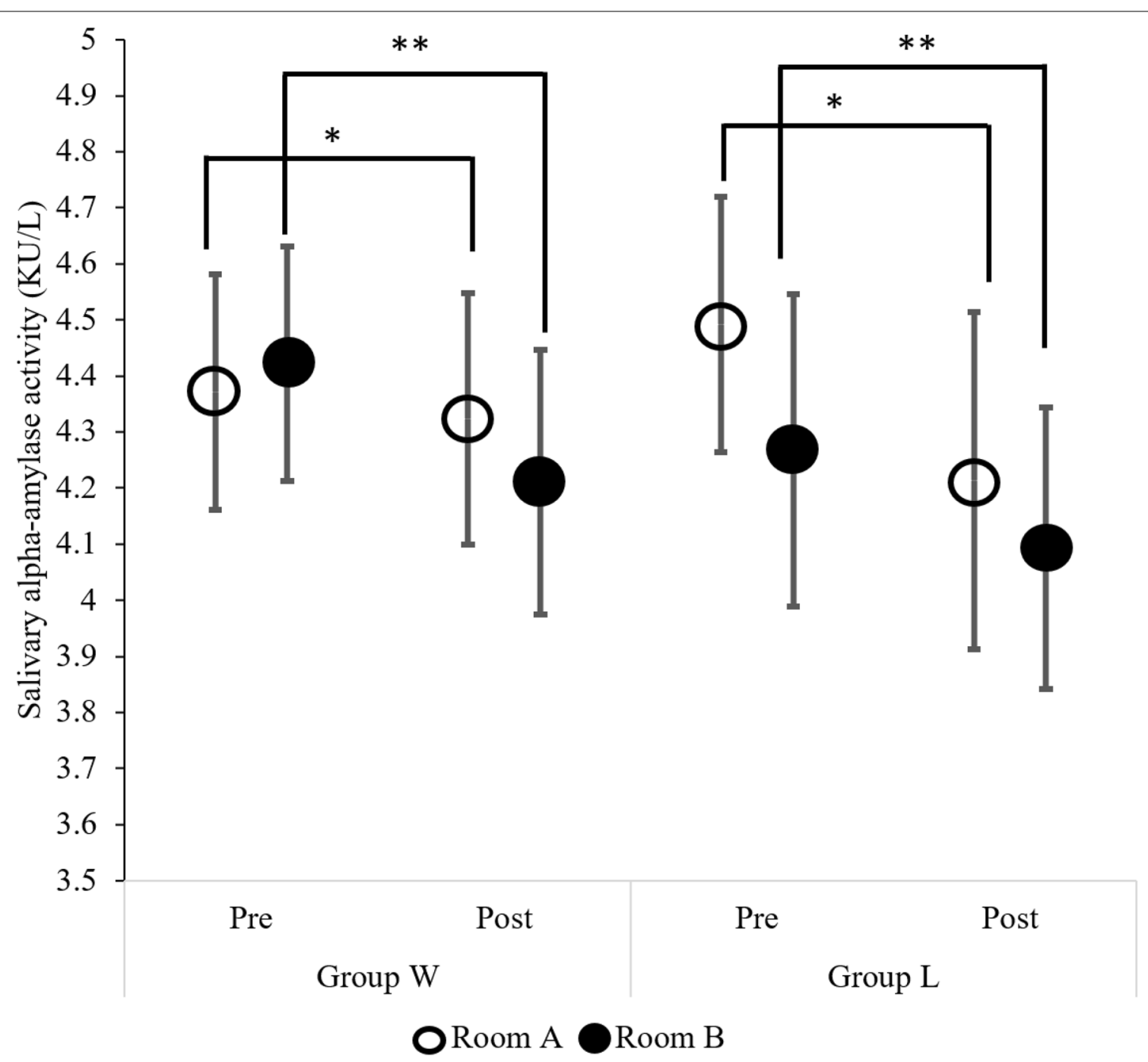

Fig. 3 The variation in salivary alpha-amylase (SAA) activity for the rooms $A$ and $B$ at the pre- (entering) and post- (exiting) measurements in the $W$ and $L$ groups. The points represent the change in room $A$ (white) and B (black) in the $W$ and $L$ groups. Compared to the pre-condition, the SAA activity of both the $\mathrm{W}$ and $\mathrm{L}$ groups was lower at the post-measurement. Data are mean $\pm 95 \% \mathrm{CI}$. MANOVA; ${ }^{* *} p<0.01,{ }^{*} p<0.05$

2 was thus designated as 'texture.' Adjectives comprising factor 3 were related to the subjects' feelings about the room; thus, factor 3 was designated as 'impression.' Finally, adjectives comprising factor 4 were related to the subjects' olfactory evaluation; factor 4 was, therefore, designated as 'smell.'

For the SD questionnaire, in the case of the factor score of factor 1 , an interaction was found between room and group. The score of the W group for Room A was higher than that for Room B, and the opposite was true for the L group. Regarding factor 2, there was a significant main effect of room; this effect shows that if we ignore the group, Room A still rated significantly higher than Room $\mathrm{B}$. In addition, the $\mathrm{W}$ group subjects gave a higher score to Room A than Room B. For factor 3, an interaction was found between room and group. The W group's score for Room A was higher than that for Room B, and the opposite was true of the L group. In the case of factor 4 , a marginal interaction was found between room and group. The L group's for Room B was marginally higher than that for Room A (Table 2).

The questionnaire on the character of the smell in each room was comprised of nine pairs of adjectives. The eigenvalue was assumed to be $\geq 1$. Three repetitions resulted in the end of the rotation, and two explicable factors were extracted. Table 4 provides the extracted factors and factor loadings. The initial eigenvalues showed that factor 1 was 3.58 , and factor 2 was 2.01 . The 


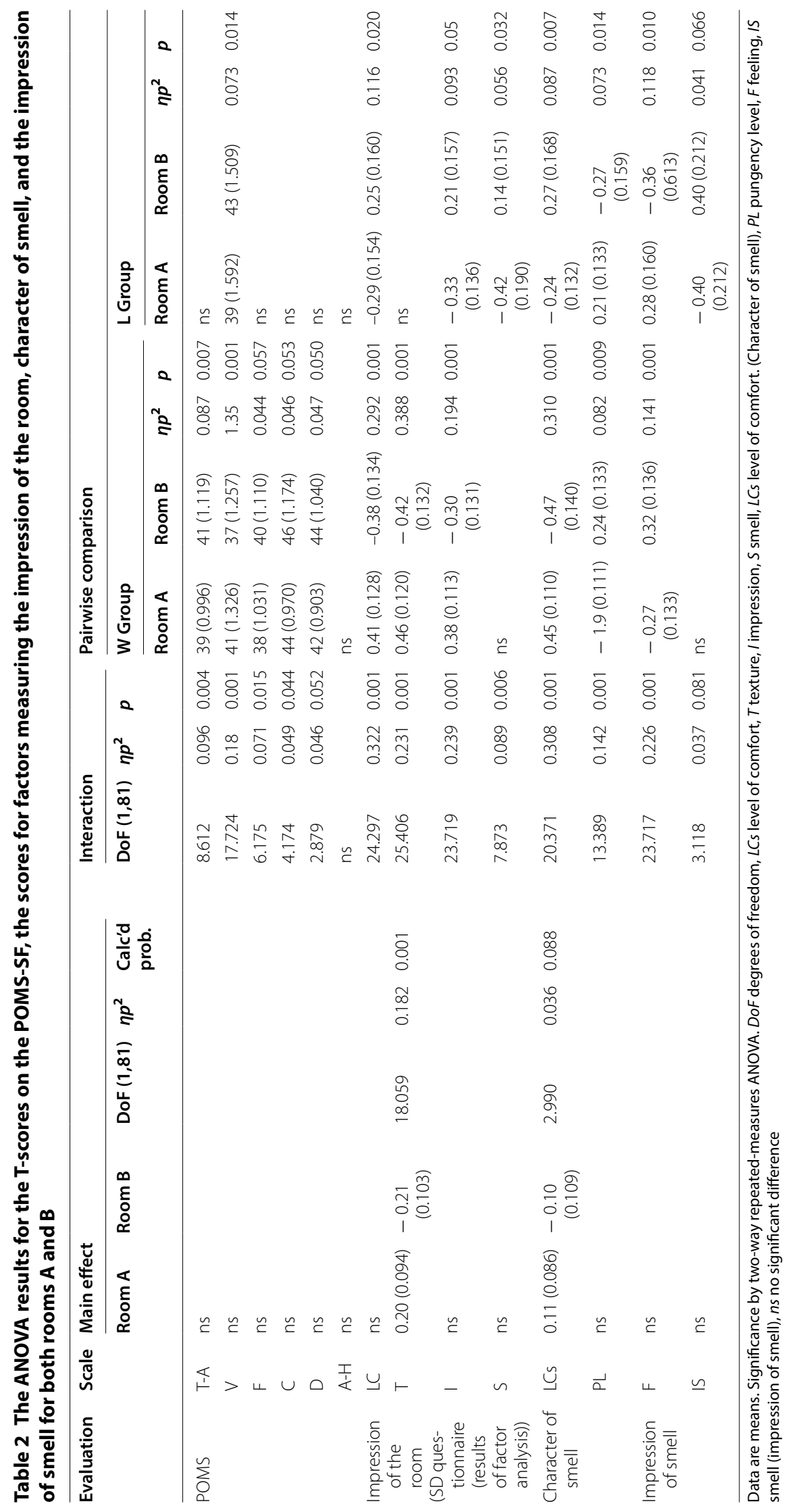


Table 3 Extracted factors and factor loadings of semantic difference questionnaire for rooms A and B

\begin{tabular}{|c|c|c|c|c|c|}
\hline \multirow[t]{2}{*}{ Evaluated item } & \multicolumn{4}{|c|}{ Factor loading } & \multirow[t]{2}{*}{ Interpretation } \\
\hline & Factor 1 & Factor 2 & Factor 3 III & Factor 4 & \\
\hline Comfortable-uncomfortable & 0.96 & 0.04 & -0.13 & -0.02 & Level of comfort \\
\hline Calm-tension & 0.91 & 0.24 & -0.21 & -0.02 & \\
\hline Not tired-tired & -0.71 & 0.12 & -0.05 & -0.13 & \\
\hline $\begin{array}{l}\text { (feel can do work) } \\
\text { Well-not well }\end{array}$ & 0.57 & -0.16 & 0.32 & 0.04 & \\
\hline Accessible-inaccessible & 0.53 & 0.00 & 0.40 & -0.01 & \\
\hline (smell) Refreshed-unrefreshed & 0.48 & -0.05 & 0.23 & 0.26 & \\
\hline Cold-warm & 0.47 & 0.12 & 0.24 & -0.22 & \\
\hline (visual) Light-heavy & -0.19 & 0.94 & 0.04 & 0.06 & Texture \\
\hline (visual) Refreshed-unrefreshed & -0.06 & 0.65 & 0.21 & 0.07 & \\
\hline Bright-dark & 0.23 & 0.64 & -0.14 & 0.02 & \\
\hline Soft-hard & 0.34 & 0.46 & -0.01 & -0.04 & \\
\hline (smell) Natural-artificial & 0.25 & -0.01 & 0.58 & -0.07 & Impression \\
\hline (visual) Natural-artificial & 0.03 & 0.36 & 0.44 & -0.11 & \\
\hline Simple-intricate & -0.06 & 0.03 & 0.44 & -0.09 & \\
\hline Secure-insecure & 0.37 & 0.00 & 0.37 & -0.10 & \\
\hline (smell) Light-strong & -0.01 & 0.00 & 0.41 & -0.69 & Smell \\
\hline (smell) Light-heavy & 0.12 & 0.15 & 0.19 & 0.67 & \\
\hline Eigenvalue & 7.71 & 1.53 & 1.31 & 1.02 & \\
\hline Contribution rate (\%) & 45.36 & 9.00 & 7.68 & 6.02 & \\
\hline Accumulated contribution rate (\%) & 45.36 & 54.36 & 62.04 & 68.06 & \\
\hline
\end{tabular}

Factor extraction method: maximum likelihood method, rotation method: promax rotation method (eigenvalue adopts 1 or more)

two-factor solution explained $62.10 \%$ of the variance. The adjectives comprising factor 1 were related to how the subjects felt when they perceived the smell in the rooms;

Table 4 Extracted factors and factor loadings of character of smell questionnaire for rooms $A$ and $B$

\begin{tabular}{lccc}
\hline \multirow{2}{*}{ Evaluated item } & \multicolumn{2}{c}{ Factor loading } & Interpretation \\
\cline { 2 - 3 } & Factor 1 & Factor 2 II & \\
\hline Refresh & 0.87 & -0.03 & Level of comfort \\
Fresh & 0.81 & 0.20 & \\
Soft & 0.75 & -0.27 & \\
Calm & 0.72 & -0.36 & \\
Perfumed & 0.62 & 0.43 & \\
Sweet & 0.48 & 0.20 & \\
Spicy & 0.09 & 0.70 & Pungency level \\
Bitter & 0.06 & 0.62 & \\
Sour & 0.11 & 0.51 & \\
Eigenvalue & 3.58 & 2.01 & \\
Contribution rate (\%) & 39.72 & 22.38 & \\
Accumulated contribu- & 39.72 & 62.10 & \\
tion rate (\%) & & & \\
\hline
\end{tabular}

Factor extraction method: maximum likelihood method, rotation method: promax rotation method (eigenvalue adopts 1 or more) thus, factor 1 was designated the 'level of comfort.' The adjectives comprising factor 2 were related to how pungent subjects felt the smell was; we thus designated factor 2 as the 'pungency level' (Table 4).

Regarding the questionnaire on the character of the smell, in the case of the factor score of factor 1, a marginal main effect of room was observed. Room A was rated significantly higher than Room $B$. In addition, the interaction between room and group was reflected by the finding that the W group gave Room A higher scores than they did for Room B, and the L group gave Room $\mathrm{B}$ higher scores. Regarding factor 2, a significant interaction between room and group was observed; the $\mathrm{W}$ group's scores for Room A were lower than those they gave Room B, and the opposite was true of the L group (Table 2).

The questionnaire on the impression of the smell had seven pairs of adjectives. The eigenvalue was assumed to be $\geq 1$. Three repetitions resulted in the end of the rotation, and two explicable factors were extracted. Table 5 lists the extracted factors and factor loadings. The initial eigenvalues showed that factor 1 was 3.48 , and factor 2 was 1.90 . The two-factor solution explained $76.76 \%$ of the variance. The adjectives comprising factor 1 were related to the subjects' impressions of the smell; thus, factor 1 
Table 5 Extracted factors and factor loadings of impression of smell questionnaire for rooms $A$ and $B$

\begin{tabular}{|c|c|c|c|}
\hline \multirow[t]{2}{*}{ Evaluated item } & \multicolumn{2}{|c|}{ Factor loading } & \multirow[t]{2}{*}{ Interpretation } \\
\hline & Factor $1 \mathrm{I}$ & Factor 2 II & \\
\hline Comfortable-uncomfortable & 0.98 & 0.06 & Impression \\
\hline Like-dislike & 0.91 & -0.01 & \\
\hline Calm-tension & 0.90 & 0.01 & \\
\hline Plain-over powered & 0.51 & -0.40 & \\
\hline Fresh-unfresh & 0.49 & 0.16 & \\
\hline Concentrated-diluted & 0.00 & 0.91 & Smell \\
\hline Strong-faint & 0.14 & 0.87 & \\
\hline Eigenvalue & 3.48 & 1.90 & \\
\hline Contribution rate (\%) & 49.70 & 27.07 & \\
\hline $\begin{array}{l}\text { Accumulated contribution } \\
\text { rate }(\%)\end{array}$ & 49.70 & 76.76 & \\
\hline
\end{tabular}

Factor extraction method: maximum likelihood method, rotation method: promax rotation method (Eigenvalue adopts 1 or more)

was designated as 'impression.' The adjectives comprising factor 2 were related to how strong the subjects felt the smell was; factor 2 was, therefore, designated as 'smell' (Table 5).

Concerning the subjects' impression of the smell, a comparison of factor 1 showed an interaction between room and group. Room A received lower scores from the W group compared to Room B. Room B received lower scores from the L group compared to Room A. Regarding factor 2, there was a marginal interaction between room and group, The L group's scores for Room B were higher than those for Room A, but no significant difference was found for the W group (Table 2).

We also observed significant differences in the group of 51 females (Wilcoxon signed ranks test). The female subjects rated Room A more 'comfortable' ( $72 \pm 5$ vs. $63 \pm 6, t=2.593, p=0.012)$, more 'calm' ( $72 \pm 6$ vs. $63 \pm 6$, $t=2.772, p=0.008)$, and more 'bright' ( $69 \pm 6$ vs. $51 \pm 6$; $t=4.445, p=0.001$ ) than Room B. No significant difference was found in the male group.

\section{Temperature, humidity, and VOCs}

There was no significant between-room difference in the temperature (room A: $17.6 \pm 0.5{ }^{\circ} \mathrm{C}$, room B: $17.5 \pm 0.5{ }^{\circ} \mathrm{C}, t(\mathrm{~F})=0.126$ (330), $p=0.900$ ) or humidity (room A: $47.1 \pm 1.6 \%$, room B: $49.1 \pm 2.9 \%, t(\mathrm{~F})=-1.63$ (330), $p=0.105$ ).

The concentrations of all sesquiterpenes in Room A were higher than those in Room B (Table 6). In both rooms, the component with the highest level was $\delta$-cadinene. The concentrations of $\delta$-cadinene, $\alpha$-cubebene, $\beta$-caryophyllene, $\alpha$-humulene, $\gamma$-cadinene,
Table 6 The concentrations $\left(\mu \mathrm{g} / \mathrm{m}^{3}\right)$ of the components and contents of VOCs emitted from Room A (planed Japanese cedar lumber) and Room B (printed grain resin sheet overlay boards)

\begin{tabular}{|c|c|c|c|c|}
\hline No. & Compound & Room A & Room B & $p$ \\
\hline 1 & a-Cubebene & $37.30 \pm 13.39$ & $14.54 \pm 2.64$ & $0.045^{* *}$ \\
\hline 2 & a-Copaene & $22.68 \pm 8.00$ & $13.13 \pm 2.37$ & 0.119 \\
\hline 3 & $\beta$-Elemene & $14.98 \pm 5.59$ & $8.45 \pm 1.67$ & 0.125 \\
\hline 4 & $\beta$-Caryophyllene & $16.61 \pm 5.50$ & $5.07 \pm 1.13$ & $0.024^{* *}$ \\
\hline 5 & cis-Thujopsene & $3.44 \pm 1.21$ & $3.04 \pm 0.48$ & 0.622 \\
\hline 6 & cis-Muurola-3,5-diene & $2.40 \pm 1.19$ & $0.74 \pm 0.06$ & 0.073 \\
\hline 7 & a-Humulene & $8.96 \pm 2.89$ & $4.06 \pm 0.72$ & $0.046^{* *}$ \\
\hline 8 & y-Cadinene & $6.78 \pm 1.83$ & $1.34 \pm 0.64$ & $0.008^{* * *}$ \\
\hline 9 & ү-Muurolene & $6.15 \pm 2.15$ & $4.93 \pm 0.68$ & 0.400 \\
\hline 10 & $\begin{array}{l}\text { trans-Muurola-4(14),5- } \\
\text { diene }\end{array}$ & $24.56 \pm 9.08$ & $6.73 \pm 1.86$ & $0.029^{* *}$ \\
\hline 11 & a-Muurolene & $37.26 \pm 12.54$ & $28.22 \pm 6.95$ & 0.336 \\
\hline 12 & $\delta$-Cadinene & $73.65 \pm 25.26$ & $28.62 \pm 8.84$ & $0.043^{* *}$ \\
\hline 13 & Calamenene & $26.25 \pm 9.42$ & $22.40 \pm 5.71$ & 0.577 \\
\hline
\end{tabular}

$p<0.05$ by Student's $t$ test. ${ }^{* * *} p<0.01,{ }^{* *} p<0.05$

and trans-muurola-4(14),5-diene in Room A were significantly higher than those in Room B.

\section{Discussion}

The results of the present study demonstrated that the subjects' systolic blood pressure decreased in the room with Japanese cedar boards, their pulse rate decreased in the room with particleboard, and their salivary alphaamylase activity was repressed in both rooms. The subjects' subjective evaluation of each room was highly dependent on their preference; each room received more positive evaluation from the subjects who liked it. However, although the subjects' feelings were also influenced by their preference, the room with Japanese cedar boards did not elicit negative feelings, even from the subjects who disliked it.

Here, all of the subjects showed decreased SBP after their stay in Room A, and this result corresponds with those of previous studies $[3,7,10]$. In contrast, no significant difference in SBP occurred after the subjects stayed in Room B. We, thus, speculate that VOCs from solid natural wood can suppress SBP regardless of the subjects' subjective preference. On the other hand, although the pulse rate of both the $\mathrm{L}$ - and $\mathrm{W}$-preferring groups decreased significantly in Room B (medium effect size, $\eta p^{2}=0.077>0.06$ ), the change was only 1 beat per minute. The effect of the room on this physiological response can, thus, be considered limited.

Since the temperature and humidity were not significantly different between the rooms, we could exclude 
their influence. The subjects' SAA values were decreased in both rooms; the SAA can be used to evaluate the sympathetic nervous/adrenal medullary system (SAM system) $[19,20]$. Previous studies of woody spaces showed that in subjects performing arithmetic work, the SAA was lower in a room with Japanese cedar than in one without [6]. When subjects performed arithmetic in rooms with different quantities of Japanese cedar board compared to a room without Japanese cedar, the rooms with Japanese cedar suppressed the increase of SAA, but the efficiency of SAA suppression was not linked to the quantity of the Japanese cedar board [6].

Another study reported that when subjects stayed in rooms with different quantities of Japanese cedarwood, i.e., Hiba (Thujopsis dolabrata) for $30 \mathrm{~min}$, no significant difference was found in physiological markers between the rooms [21]. Our present analyses revealed that the SAA values of the subjects in both rooms A and B were suppressed. Both of these rooms had wooden interiors, but the ratios of compounds in the rooms were different. It has been suggested that VOCs from wood material can suppress the SAA regardless of the ratio and subjective preference.

Our subjects' POMS-SF results showed no main effect of room in any sub-scale except Anger-Hostility; however, the other five subscales, i.e., Tension-Anxiety, Depression, Fatigue, Vigor, and Confusion were found to interact with room preference. This means that the subjects' mood was relatively affected by their preference for one room over the other. Moreover, the subjects who preferred Room A scored lower on the four subscales other than Vigor when staying in Room A compared to their scores for Room B. This suggests that the (woodpreferring) subjects in the $\mathrm{W}$ group felt less TensionAnxiety, Depression, Fatigue and Confusion in Room A than in Room B. No corresponding significant differences were observed in the (laminate-preferring) L group. On the other hand, for the positive scale Vigor, the $\mathrm{W}$ group gave Room A a higher score, whereas the L group gave Room B a higher score. We thus conclude that the positive scale of subjective mood status can be influenced by one's personal preference, but the negative scale of subjective mood status can be relieved by the presence of solid natural wood.

The impression evaluation results show the effects of personal preference on the subjects' assessments. In the case of the 'level of comfort,' 'impression,' and 'smell', both the $\mathrm{L}$ and $\mathrm{W}$ groups gave their preferred room a higher score. However, both groups gave Room A a higher score on 'texture.' Previous investigations related to the visual effects of wood material reported that impressions changed depending on the quantity of the wood material [22]. When the number of knots in todomatsu wood increased, the subjects' positive evaluation of the wood decreased [23]. To the best of our knowledge, however, no prior investigation focused on impressions other than appearance. Our subjects' questionnaire responses regarding the character of the smell in the rooms showed that the scores for 'strength of smell' and 'pungency' depended on the subjects' room preferences. Both the L and $\mathrm{W}$ groups evaluated the room they did not prefer as having more 'pungency' and a 'stronger' smell. The reason for the negative evaluation could be ascribed to their feeling that the smell was too strong or that they disliked the smell. The subjects' positive evaluations were associated with comments like 'smells good,' 'decent smell', and 'relaxing.' The subjects' subjective evaluation was influenced by their personal background and health and the VOC ratio of each compound. A study of child subjects reported that the smell of cypress induced an image of pesticides and received a low evaluation [24].

Our present findings revealed that the Japanese cedar and laminate rooms had the same types of volatile organic compounds. This was also observed in another study [13], and we suspect that the reason for this is that high-temperature dried Japanese cedar wood was used as the structural material of the laminate room. Our present investigation differs from a report that that airdried, conventionally dried, and high-temperature dried Japanese cedar wood chips emitted different VOCs [25]. Some of the reasons for these differences may be differences in the analytical methods used, including differences in the sorbent tubes used to collect VOCs. In this study, we detected the same terpenes in the two rooms. Furthermore, the peaks of components other than terpenes were so small that it was difficult for us to find a sufficient difference between the VOCs of the rooms. Therefore, the difference between psychological response and subjective assessment may have been caused by different amounts of terpenes.

The concentrations of $\alpha$-cubebene, $\beta$-caryophyllene, cis-muurola-3,5-diene, $\gamma$-cadinene, $\quad$ trans-muurola$4(14) 5$-diene, and $\delta$-cadinene were higher in Room A. $\delta$-cadinene and $\alpha$-muurolol, components of the essential oil of Cananga odorata, regulate human autonomic nervous system (ANS) activity via the stimulation of parasympathetic nerve system (PSNS) activity [26]. The $\delta$-cadinene and $\alpha$-muurolol present in Meniki (Chamaecyparis formosensis) essential oil might be the factors in the increase of PSNS activity; it is possible that Meniki essential oil could improve ANS activity via an increase in HRV [27]. $\delta$-cadinene was abundant in our room A and our results, thus, suggest that $\delta$-cadinene influenced the physiological response and subjective evaluations.

Differences in the concentrations of VOCs may well have influenced our subjects' subjective evaluations. 
Since no single compound was isolated for evaluation, we could not distinguish which compound(s) had the effects, or the mechanisms of the effects. However, for the item 'comfort of smell', all subjects gave Room A a higher score than Room B, which suggests that all of the subjects found the Japanese cedar room more comfortable compared to the room with artificial materials.

Both rooms had nearly the same appearance o eliminate the influence of visual effects, and none of the subjects mentioned knots or any visual features in their responses to the questionnaires after the experiments.

In addition, when we compared the females and males regardless of the subjects' preferences, differences in the subjective ratings of comfort, calm, and brightness between the rooms were revealed in the group of female subjects, suggesting that females may perceive indoor environments differently from males. The male subjects did not report any difference in the aforementioned three subscales between the Japanese cedar and artificial rooms. Thus, men may be less sensitive to the living environment than women.

\section{Conclusions}

We investigated the effects of two rooms with different types of wood material on subjects' physiological responses and subjective evaluations. In terms of physiological responses, no parameter was influenced by the subjects' personal preference. The subjects' blood systolic pressure decreased significantly in the room with planed Japanese cedar lumber, which seemed to have a stronger influence on the subjects' physiological responses than the room with printed grain resin sheet overlay boards. These findings may have been obtained because the Japanese cedar boards had different concentrations of some types of terpenes compared to the printed grain resin sheet overlay boards. For the subjective evaluation, the subjects' personal preferences showed a clear influence (except for the evaluation of visual texture). The subjects' evaluation of visual quality was not related to their personal preferences. Though the moods of the subjects were influenced by their personal preferences, the room with planed Japanese cedar lumber received a more positive evaluation than the room with printed grain resin sheet overlay boards; thus, negative mood changes could be suppressed more efficiently in the room with planed Japanese cedar lumber.

Our findings verify some of the effects of wood VOCs reported previously in fully controlled experimental settings in realistic circumstances, such as spaces in which people performed casual deskwork. The results indicate that people's physiological responses were not in accordance with their subjective evaluations. Analyses of physiological responses are, thus, important to ensure the validity of similar assessments. Further research that uses experimentally controlled stressors or attentiondepleting tasks in two rooms with different wood materials is necessary to verify possible restorative properties of wood interiors.

\section{Limitations}

Although we prepared the two rooms so that they would have almost the same appearance to eliminate the influence of visual effects, some of the subjects described feeling visual differences between the two rooms. Some subjects may have sensed some difference since the two rooms' doors had different outside surfaces; we also did not test the effect of the room-exposure order. We also did not detect enough of the components other than the terpenes to identify them, and this we did not compare those other components between the two rooms. We, therefore, could not consider the influence of VOCs derived from artificial materials used in Room B, such as glues.

\begin{abstract}
Abbreviations
ANS: Autonomic nervous system; 1- $\beta$ : 1- $\beta$ error probability of statistical test; GC/MS: Gas chromatography-mass spectrometry; HF: High-frequency; HRV: Heart rate variability; L group: Group preferred Laminate; LF: Low-frequency; LOQ: Limit of quantification; MANOVA: Multivariate analysis of variance; MDF: Medium density fiberboard; POMS: Profile of mood states; PSNS: Parasympathetic nerve system; SAA: Salivary alpha-amylase; SAM: Sympathetic nervous/ adrenal medullary; SBP: Systolic blood pressure; SD: Semantic differential; SS: Sum of squares; TDU: Thermal desorption unit; VAS: Visual analog scale; VOCs: Volatile organic compounds; W group: Group preferred Wood; $n p^{2}$ : Partial eta-squared.
\end{abstract}

\section{Acknowledgements}

We thank all subjects for their participation.

\section{Authors' contributions}

SMK analyzed and interpreted the data and was a major contributor in writing the manuscript. All authors read and approved the final manuscript.

\section{Funding}

This research was supported by Grants-in-Aid for the new products, technological developments, and extension services for the naturalization of cities (Japan Forestry Agency, 2013-2016) and Zhejiang Provincial Natural Science Foundation of China under Grant No. LY19E080015

\section{Availability of data and materials}

The datasets generated during and analyzed in this study are available from the corresponding author on reasonable request.

\section{Competing interests}

The authors declare that they have no competing interests.

\section{Author details}

${ }^{1}$ Faculty of Agriculture, Kyushu University, 744 Motooka, Nishi-ku, Fukuoka 819-0395, Japan. ${ }^{2}$ School of Architecture and Urban Planning, Suzhou University of Science and Technology, Suzhou, China. ${ }^{3}$ Department of Biological Resources Management, The University of Shiga Prefecture, Hikone, Japan. ${ }^{4}$ TRYWOOD Co., Ltd., Hita, Japan. ${ }^{5}$ YASUNARI CORPORATION, Shimonoseki, Japan. ${ }^{6}$ Faculty of Arts and Science, Kyushu University, Fukuoka, Japan. ${ }^{7}$ Center for Health Sciences and Counseling, Kyushu University, Fukuoka, Japan. ${ }^{8}$ International College of Arts and Sciences, Fukuoka Women's 
University, Fukuoka, Japan. ${ }^{9}$ Faculty of Humanity-Oriented Science and Engineering, Kindai University, lizuka, Japan.

Received: 1 June 2020 Accepted: 3 September 2020

Published online: 14 September 2020

\section{References}

1. Nishimura M, Ikaga S, Hirata J, Ogawa S, Tsutiya R (2016) Influence of woody sleep scape to sleep and Intellectual productivity. Kanto Chapter Archit Inst Jpn 86(2):225-228

2. Kimura A, Sugiyama H, Sasaki S, Yatagai M (2011) Psychological and physiological effects in humans induced by the visual and olfactory stimulations of interior environment made of Hiba (Thujopsis dolabrata) wood. Mokuzai Gakkaishi 57(3):150-159

3. Tsunetsugu Y, Morikawa T, Miyazaki Y (2005) Relaxation Effect of Smell of Wood. Wood Ind 60(11):598-602

4. Yatagai M (2007) Aromas of forests and trees, their characteristics and functions. J Jpn Assoc Odor Environ 38(6):428-434

5. Yatagai M (2014) Usage of aromas of Japanese cedar (Cryptomeria japonica). Akita Prefect Univer Web J 1:151-157

6. Matsubara E, Kawai S (2014) VOCs emitted from Japanese cedar (Cryptomeria japonica) interior walls induce physiological relaxation. Build Environ 72:125-130

7. Kawai S, Miyakoshi J, Nakamura M, Azuma K, Bamba I, Kimura A, Kagawa M, Tsujino Y, Uebori M, Ohyama M, Miyake H, Fujita S, Nakayama M (2012) Characterization of air purification function of Japanese cedar wood and its effects on the visual psychological and physiological factors. Humanosphere Res 8:55-68

8. Ikei H, Song C, Miyazaki Y (2015) Physiological effect of olfactory stimulation by Hinoki cypress (Chamaecyparis obtusa) leaf oil. J Physiol Anthropol 34:44

9. Tsunetsugu Y, Park BJ, Miyazaki Y (2012) Physiological effects of visual, olfactory, auditory, and tactile factors in the forest environment. In: Li Q (ed) Forest medicine. Nova Science Publishers Inc, New York, pp 169-181

10. Kim YK, Hagino I, Shibayama Y, Watanuki S (2000) The effect of wooden essential oil's odor on psychophysiological responses. Jpn J Physiol Anthropol 5:20-21

11. Gohara T, Iwashita T (2001) Influence of wood aroma to human perceptive air quality. Proc Symp Hum Environ Syst 25:191-194

12. Ministry of Agriculture, Forestry and Fisheries (2014) Japanese agricultural and forestry standards for plywood. https://www.maff.go.jp/j/jas/ jas_kikaku/pdf/kikaku_53.pdf. Accessed 1 Dec 2019

13. Shimizu K, Yoshimura Y, Nakagawa T, Matsumoto S, Washioka Y, Haga E, Honden A, Nakashima T, Saijo H, Fujita K, Watanabe Y, Okamoto G, Inoue S, Yasunari S, Nagano J, Yamada Y, Okamoto T, Onuki K, Ishikawa H, Fujimoto N (2017) Analysis of volatile compounds and their seasonal changes in rooms using Sugi (Cryptomeria japonica) wood boards as interior materials. Mukuzai Gakkaishi 63(3):126-130

14. Sadaaki O, Masao I (1961) Measurement of the color effect of building by the semantic differential method. Trans Archit Inst Jpn 67:105-113
15. Terauchi F, Aoki H, Ohgama T, Kubo M, Suzuki T (1994) Evaluation of odors from woods and wood oils: odors from extracts using supercritical carbon dioxide and essential oils by hot water distillation from coniferous woods. Bull Jpn Soc Sci Design 41(1):11-18

16. Yokoyama K (2005) Instruction and case commentary of short version of POMS. Kaneko Shobo, Tokyo

17. Cohen J (1988) Statistical power analysis for the behavioural sciences, 2nd edn. Academic Press, New York, pp 280-287

18. Olejnik S, Algina J (2000) Measures of effect size for comparative studies: applications, interpretations, and limitations. Contemp Educ Psychol 25(3):241-286. https://doi.org/10.1006/ceps.2000.1040

19. Charney DS (2014) Psychobiological mechanisms of resilience and vulnerability: implications for successful adaptation to extreme stress. Am J Psychiatry 161:195-216. https://doi.org/10.1176/appi.ajp.161.2.195

20. Speirs RL, Herring J, Cooper WD, Hardy CC, Hind CR (1974) The influence of sympathetic activity and isoprenaline on the secretion of amylase from the human parotid gland. Arch Oral Biol 19:747-752

21. Kimura A, Sasaki S, Kobayashi D, lijima Y, Yatagai M (2011) The effect of room interiors with different wood quantities on task efficiency during two-digit addition and subtraction. Mokuzai Gakkaishi 57(3):160-168

22. Sakuragawa S (2006) Change in the impression of rooms with interior wood finishes arranged differently: questionnaire survey with the use of photographs for the analysis of impression of room concerning living activates. J Wood Sci 52(4):290-294. https://doi.org/10.1007/s1008 6-005-0764-1

23. Matsumoto K, Kawato K, Saito N, Sasaki M, Kawabata Y (2016) Preference evaluation based on cognitive psychology of the quantity of knots present in wood wall panels I: effects of the ratio of knot area of todomatsu wall panels and of room type on people's preferences for residential living rooms. Mokuzai Gakkaishi 62:42-48. https://doi.org/10.2488/ jwrs.62.42

24. Fukuda H, Nakamine M (2003) Change in Feelings by Perfume of Essential Oils: sensory evaluation of odour preference for wood essential oils by children. Wood Ind 58(12):593-597

25. Ohira Tatsuro, Park Bum-Jin, Kurosumi Yoshitomo, Miyazaki Yoshifumi (2009) Evaluation of dried-wood odors: comparison between analytical and sensory data on odors from dried sugi (Cryptomeria japonica) wood. J Wood Sci 55(2):144-148

26. Jones EA (2010) Awaken to healing fragrance. In: The power of essential oil therapy, North Atlantic Books, California, p 175

27. Chen CJ, Senthil Kumar KJ, Chen YT, Tsao NW, Chien SC, Chang ST, Chu FH, Wang SY (2015) Effect of Hinoki and Meniki essential oils on human autonomic nervous system activity and mood states. Nat Prod Commun 10:1305-1308. https://doi.org/10.1177/1934578X1501000742

\section{Publisher's Note}

Springer Nature remains neutral with regard to jurisdictional claims in published maps and institutional affiliations.

\section{Submit your manuscript to a SpringerOpen ${ }^{\odot}$ journal and benefit from:}

- Convenient online submission

- Rigorous peer review

- Open access: articles freely available online

- High visibility within the field

- Retaining the copyright to your article

Submit your next manuscript at $\boldsymbol{\nabla}$ springeropen.com 